\title{
KEPATUHAN PRAKTISI TERAPI TRADISIONAL BEKAM TERHADAP STANDAR PROSEDUR OPERASIONAL
}

\author{
Tri Wahyuni Lestari', Lusitawati ${ }^{2}$, Annisa Rizky A3 ${ }^{3}$ FX. Suharyanto ${ }^{4}$, Nita Prihartini ${ }^{5}$, Nurhayati ${ }^{6}$, \\ Hadi Siswoyo ${ }^{7}$
}

Pusat Penelitian dan Pengembangan Sumber Daya dan Pelayanan Kesehatan

Badan Litbang Kesehatan Jakarta, Indonesia. E - mail: wahyuni_lestari29@yahoo.com

\section{ABSTRACT: WET CUPPING THERAPY PRACTITIONER AND STANDARD OPERATING PROCEDURES}

Background: Traditional wet cupping therapy is an invasive alternative therapy in the community. To ensure its safety, it is necessary to conduct research on the compliance of wet cupping practitioners against the Standard Operating Procedure (SOP).

Purpose: To obtain an overview of the compliance of cupping therapy practitioners with the Standard Operating Procedure (PSO) in DKI Jakarta.

Methods: This study was a cross-sectional study, conducted on 30 wet cupping practitioners in the DKI Jakarta area who fulfilled the inclusion and exclusion criteria. The method of data collection is done by observing cupping practitioners, each of them 3 times to avoid bias behavior of respondents who deliberately do it because they are being observed. Data analysis was carried out descriptively and analytically. Test the relationship between independent and dependent variables is done to determine the factors associated with compliance.

Conclusion: The average value of compliance with cupping practitioners in the PBI member of DKI Jakarta against PSO is 81.47 percent. Factors related to the compliance of cupping therapy members of the Jakarta DKI Cupping Association (PBI) towards Standard Operating Procedure (PSO) there are 3 variables, namely the year passed the standardization test, facilities and supervision.

\section{Keywords: compliance, wet cupping, Standard Operating Procedure}

Pendahuluan: Terapi tradisional bekam merupakan terapi alternatif yang bersifat invasif yang ada di masyarakat. Untuk memastikan keamanannya maka perlu dilakukan penelitian mengenai kepatuhan para praktisi bekam terhadap Prosedur Standar Operasi (PSO).

Tujuan: memperoleh gambaran kepatuhan para praktisi terapi bekam terhadap Standar Prosedur Operasional (PSO) di DKI Jakarta.

Metode: Penelitian ini merupakan penelitian dengan desain cross sectional, dilakukan pada 30 orang praktisi bekam di wilayah DKI Jakarta yang memenuhi kriteria inklusi dan ekslusi. Cara pengumpulan data dilakukan dengan observasi terhadap praktisi bekam, masing-masing sebanyak 3 kali untuk menghindari bias perilaku responden yang sengaja dilakukan karena mengetahui sedang diamati. Analisis data dilakukan secara deskriptif dan analitik. Uji hubungan antar variabel independen dan dependen dilakukan untuk mengetahui faktor-faktor yang berhubungan dengan kepatuhan.

Simpulan: Nilai rata-rata kepatuhan praktisi bekam anggota PBI DKI Jakarta terhadap PSO yaitu 81,47 persen. Faktor-faktor yang berhubungan dengan kepatuhan praktisi terapi bekam anggota Perkumpulan Bekam Indonesia (PBI) DKI Jakarta terhadap Prosedur Standar Operasi (PSO) ada 3 variabel yaitu tahun lulus uji standardisasi, sarana prasarana dan supervisi.

\section{Kata kunci : kepatuhan, bekam, Standar Prosedur Operasi (PSO)}

\section{PENDAHULUAN}

Undang-undang no 36 tahun 2009 tentang Kesehatan, Pasal 47 yaitu: Upaya kesehatan diselenggarakan dalam bentuk kegiatan dengan pendekatan promotif, preventif, kuratif dan rehabilitatif yang dilaksanakan secara terpadu, menyeluruh dan berkesinambungan. Pasal 48 ayat (1) point b: Penyelenggaraan upaya kesehatan sebagaimana dimaksud dalam Pasal 47 salah satunya dilaksanakan melalui kegiatan pelayanan kesehatan tradisional. Metode pengobatan tradisional yang terdapat di masyarakat salah satunya yaitu terapi bekam. Terapi bekam dalam hal ini adalah bekam basah merupakan terapi yang digunakan untuk mengeluarkan sejumlah darah yang mengandung zat toksik yang tidak terekskresikan oleh tubuh melalui permukaan kulit dengan cara melukai permukaan kulit. 
KEPATUHAN PRAKTISI TERAPI TRADISIONAL BEKAM TERHADAP STANDAR PROSEDUR OPERASIONAL

Pengobatan bekam di Indonesia dimulai sejak masuknya agama Islam di Indonesia dan berkembang seiring dengan kembalinya mahasiswa Indonesia yang belajar di Malaysia, India dan Timur Tengah (Fikri, Nursalam \& Has, 2017). Terapi kesehatan dengan berbekam didasarkan atas keyakinan di masyarakat, yang meyakini bahwa perintah berbekam itu datang langsung dari malaikat melalui Rosulullah, dan Rosul pun telah mengamalkan bekam untuk menjaga kesehatan (Sarkosih, 2012; Nurul, 2015; Haryanto,2008).

Beberapa penelitian yang sudah dilakukan dalam rangka membuktikan khasiat dan efek samping serta keamanan terapi bekam secara ilmiah, diantaranya yaitu penelitian yang mengevaluasi manfaat bekam untuk hipertensi pada 60 responden yang dibagi menjadi 2 kelompok yaitu 30 orang diberi terapi bekam dan 30 orang diberi terapi pijat refleksi.

Terdapat perbedaan efektivitas dalam menurunkan tekanan darah sistole, tetapi tidak ada perbedaan efektivitas dalam menurunkan tekanan darah diastole (Sari, Renityas \& Wibisono, 2014). Terapi bekam yang dilakukan selama $3 x$ selang 15 hari dapat menurunkan kadar kolesterol total secara signifikan pada 24 orang subyek dengan diabetes melitus type 2. Berbekam juga dapat meningkatkan sistem imun, hal ini terlihat pada 20 subyek yang diberi terapi bekam, 15 hari kemudian terdapat peningkatan sel makrofag dalam darah. (Widada, 2011). Dari segi keamanan terapi bekam telah diteliti dan pada prinsipnya tidak menimbulkan efek yang membahayakan tubuh dan aman diberikan pada manusia serta tidak bertentangan dengan norma yang ada (Nurul, 2015 ; Rohatami, Maliya \& Ambarwati, 2012; Sarkosih ,2012).

Terkait dengan praktik bekam di Indonesia, Kementerian Kesehatan hanya memperbolehkan praktik bekam kering (non invasif), atau dalam pengobatan tradisional Cina disebut sebagai cupping terapi, yaitu terapi dengan memberi tekanan negatif pada permukaan tubuh dengan menggunakan gelas/cup yang biasanya diterapkan pada titik akupuntur (tanpa pengeluaran darah) (Hopwood, 2013).

Namun demikian, terdapat beberapa penelitian komparatif yang membandingkan manfaat bekam basah dan bekam kering diantaranya yaitu studi komparasi bekam basah dan bekam kering terhadap 32 subyek hipertensi mengindikasikan manfaat bekam basah dapat menurunkan tekanan darah rata-rata sebesar $10,6 \mathrm{mmHg}$ dibandingkan bekam kering yang hanya dapat menurunkan tekanan darah rata-rata $2,8 \mathrm{mmHg}$. (Hermalinda, Rustina \& Novieastari, 2015).

Selain itu juga terdapat studi yang membandingkan manfaat bekam basah dan bekam kering pada 30 subyek hiperurisemia. Bekam basah dapat menurunkan asam urat secara signifikan dibanding bekam kering pada $p=0,007$ dengan $\alpha=0,05$ (Rofiq, 2016; Nurafifah \& Kusbiantoro, 2014).

Praktik bekam basah yang banyak dilakukan di Indonesia termasuk tindakan invasif karena melakukan perlukaan pada permukaan tubuh klien, hal ini tidak sesuai dengan PP 103 th 2014, pasal 27 ayat 1 , yang menyatakan bahwa tindakan invasif tidak dapat dilakukan oleh penyehat tradisional. Terapi dengan tindakan invasif hanya dapat dilakukan oleh tenaga kesehatan tradisional yang berpendidikan serendahnya diploma tiga bidang kesehatan

Selain itu keilmuan bekam juga belum didukung oleh latar belakang data-data ilmiah yang menjadi batang tubuh keilmuannya, termasuk diantaranya; kajian-kajian ilmiah yang berdasarkan evidence base, belum terdapatnya PSO yang baku dan sesuai dengan evidence base, standar kompetensi dan standar pelayanan yang belum jelas serta data kepatuhan praktisi terapi terhadap PSO yang disepakati dalam hal ini adalah PSO yang dikeluarkan oleh asosasi bekam PBI.

Hal ini sesuai dengan penelitian tentang keselamatan pasien terapi bekam yang menyatakan masih perlu diberikan pembinaan terutama dalam kompetensi terhadap para praktisi bekam karena masih terjadi kesenjangan dalam hal pendidikan dasar dan pendidikan ketrampilan bekam yang dimiliki.

(Kementrian kesehatan Republik Indonesia,2014; Sarkosih, 2012).

Kenyataan yang terlihat di masyarakat yaitu bahwa terapi bekam ini ada dan menjadi salah satu terapi alternatif untuk pemeliharaan kesehatan, hal ini terlihat dari maraknya pelatihanpelatihan bekam serta klinik-klinik bekam. Mereka meyakini bahwa darah yang dikeluarkan merupakan darah yang mengandung banyak toksin yang tidak diperlukan atau mengganggu kesehatan. Penelitian di kelurahan Pondok Benda, Pamulang menyatakan bahwa terdapat $62,6 \%$ masyarakat setempat mempunyai persepsi yang

Tri Wahyuni Lestari', Lusitawati ${ }^{2}$, Annisa Rizky $A^{3}$, FX. Suharyanto ${ }^{4}$, Nita Prihartini ${ }^{5}$, Nurhayati ${ }^{6}$,

Hadi Siswoyo ${ }^{7}$ Pusat Penelitian dan Pengembangan Sumber Daya dan Pelayanan Kesehatan

Badan Litbang Kesehatan Jakarta, Indonesia E - mail: wahyuni_lestari29@yahoo.com 
KEPATUHAN PRAKTISI TERAPI TRADISIONAL BEKAM TERHADAP STANDAR PROSEDUR OPERASIONAL

positif terhadap bekam, mereka menyadari bahwa bekam harus dilakukan oleh tenaga ahli dan memiliki kontraindikasi terhadap penyakit tertentu. Data dari asosiasi $\mathrm{PBI}$, jumlah praktisi yang menjadi anggotanya tercatat sebanyak 3700 orang di seluruh Indonesia. Namun demikian, diperkirakan masih banyak lagi praktisi yang tidak menjadi anggota asosiasi (Purboyekti, 2017).

Dalam menjalankan pekerjaannya, praktisi bekam mengeluarkan sejumlah darah dari tubuh klien dengan cara melukai permukaan tubuh (terapi invasif). Oleh karenanya, praktisi bekam dihadapkan pada risiko yang sama dengan petugas medis dalam hal paparan terhadap bahan infeksius. Petugas medis yang menangani darah atau cairan tubuh manusia akan berpotensi terinfeksi dan juga menghadapi risiko terpapar atau cedera perlukaan (Purnomo, Johan \& Rofi'i, 2016). Selain itu petugas perlu waspada pada kemungkinan terjadinya bahaya yang ditimbulkan akibat bahan bahan serta peralatan yang terinfeksi serta mengetahui bagaimana cara untuk melindungi diri, sejawat, serta lingkungannya.

Untuk itu diperlukan suatu prosedur yang sistematis untuk menjamin keselamatan petugas maupun klien, yang tertuang dalam bentuk Standard Prosedur Operasional yang disingkat dengan SPO. SPO juga dapat memberikan kemudahan kepada petugas dalam melaksanakan pekerjaannya sehingga dapat memberikan pelayanan yang bermutu dan berkualitas, disamping terhindar dari risiko terpajan atau tertular penyakit. Terapi tradisional bekam merupakan terapi alternatif yang bersifat invasif yang ada di masyarakat. Untuk memastikan keamanannya maka perlu dilakukan penelitian mengenai kepatuhan para praktisi bekam terhadap PSO yang telah ditetapkan oleh asosiasinya dalam hal ini PBI.

Adanya regulasi yg tidak merekomendasikan sehubungan dengan tindakan invasif, justru menjadi tantangan agar PBI semakin berbenah mengacu pada aturan yang ada. Dengan mempertimbangkan khasiatnya maka terapi bekam basah ini masih dapat dipertimbangkan kelangsungan keberadaanya, tentunya dengan memperhatikan risiko praktik invasif terhadap klien serta penelitian kefektifan terapi dibanding dengan terapi lainnya.(Rizkika, 2014)

Terapi bekam basah merupakan terapi dengan tindakan invasif yang bertentangan dengan PP 103 th 2014, pasal 27 ayat 1. Namun pada kenyataannya terapi ini ada dan diminati oleh masyarakat. Data dari asosiasi Perkumpulan Bekam Indonesia (PBI), jumlah praktisi yang menjadi anggotanya tercatat sebanyak 3700 orang di seluruh Indonesia. Namun demikian, diperkirakan masih banyak lagi praktisi yang tidak menjadi anggota asosiasi. Terapi ini memerlukan kehatia-hatian dalam pelaksanaanya terkait dengan keamanan klien maupun praktisinya. Untuk itu perlu dilakukan penelitian terhadap kepatuhan praktisi terapi bekam terhadap Standar Prosedur Operasional (PSO).

Penelitian ini bertujuan memperoleh gambaran kepatuhan para praktisi terapi bekam terhadap Standar Prosedur Operasional (PSO) di DKI Jakarta. Hasil penelitian ini diharapkan dapat memberi informasi mengenai gambaran kepatuhan para praktisi terapi bekam di DKI Jakarta terhadap Standar Prosedur Operasional (PSO) serta dapat memberikan masukan bagi Kementerian Kesehatan mengenai kegiatan terapi tradisional bekam di DKI Jakarta.

\section{METODE PENELITIAN}

Penelitian ini merupakan penelitian jenis potong lintang (cross sectional). Pengumpulan data baik variabel independen maupun variabel dependen dilaksanakan pada satu waktu. Penelitian ini dilaksanakan di DKI Jakarta.

Populasi adalah para praktisi terapi bekam yang tergabung dalam anggota asosiasi Perkumpulan Bekam Indonesia (PBI) di DKI Jakarta. Besar sampel ditentukan dengan menggunakan jumlah sampel minimum yaitu 30 orang praktisi bekam di wilayah DKI Jakarta yang memenuhi kriteria inklusi dan ekslusi serta dipilih secara purposif. Rumah bekam tempat para praktisi itu bekerja, dipilih dengan memperhatikan keterwakilan daerah di DKI Jakarta. Kriteria Inklusi dan Eksklusi responden yaitu praktisi bekam anggota PBI yang praktik di wilayah DKI Jakarta; memiliki lokasi praktik yang menetap dan jelas alamatnya; telah berpraktik minimal 1 tahun; menanda tangani formulir kesediaan sebagai subyek penelitian; kriteria eksklusi yaitu praktisi hanya berpraktik berdasarkan panggilan dari rumah ke rumah dan tidak bersedia ikut dalam penelitian. Analisis data dilakukan secara deskriptif dan analitik.

Sebelum melaksanakan penelitian responden yang memenuhi persyaratan akan mendapat penjelasan tentang tujuan dan manfaat dari

Tri Wahyuni Lestari', Lusitawati ${ }^{2}$, Annisa Rizky $A^{3}$, FX. Suharyanto ${ }^{4}$, Nita Prihartini ${ }^{5}$, Nurhayati ${ }^{6}$,

Hadi Siswoyo ${ }^{7}$ Pusat Penelitian dan Pengembangan Sumber Daya dan Pelayanan Kesehatan

Badan Litbang Kesehatan Jakarta, Indonesia E - mail: wahyuni_lestari29@yahoo.com 
KEPATUHAN PRAKTISI TERAPI TRADISIONAL BEKAM TERHADAP STANDAR PROSEDUR OPERASIONAL

penelitian tersebut. Saat pengisian angket ataupun kuesioner responden dipersilahkan untuk membaca lembar persetujuan (informed concent) dan apabila responden bersedia ikut dalam penelitian, responden menandatangani lembar persetujuan dan kuesioner responden.
Penelitian ini memerlukan pertimbangan etik dari Komisi Etik Penelitian Kesehatan Badan Penelitian dan Pengembangan Kesehatan Kementerian Kesehatan RI.

\section{HASIL}

Karakteristik responden praktisi dari segi usia di dominasi usia antara 31-51 tahun. Proporsi jenis kelamin responden laki-laki dan wanita seimbang. Asal wilayah responden hanya berasal dari Jakarta Selatan dan Jakarta Timur. Sebagian besar responden praktisi tidak memiliki baik STPT dan SIPT. Pendidikan formal responden didominasi dengan pendidikan SMTA. (Tabel 1) 
KEPATUHAN PRAKTISI TERAPI TRADISIONAL BEKAM TERHADAP STANDAR PROSEDUR OPERASIONAL

Tabel 1. Gambaran pendidikan dan pengalaman responden praktisi

\begin{tabular}{|c|c|c|}
\hline Karateristik Praktisi & Frekuensi & Persen \\
\hline \multicolumn{3}{|l|}{ Usia } \\
\hline $21-30$ tahun & 12 & 40,0 \\
\hline $31-50$ tahun & 15 & 50,0 \\
\hline di atas 50 tahun & 3 & 10,0 \\
\hline \multicolumn{3}{|l|}{ Jenis Kelamin } \\
\hline Laki-laki & 15 & 50,0 \\
\hline perempuan & 15 & 50,0 \\
\hline \multicolumn{3}{|l|}{ Wilayah } \\
\hline Jakarata Selatan & 13 & 43,3 \\
\hline Jakarta Timur & 17 & 56,7 \\
\hline \multicolumn{3}{|l|}{$\begin{array}{l}\text { STPT (Surat Terdaftar } \\
\text { Pengobat Tradisional) }\end{array}$} \\
\hline Memiliki & 3 & 10,0 \\
\hline Tidak memiliki & 27 & 90,0 \\
\hline \multicolumn{3}{|c|}{ SIPT (Surat Izin Pengobat } \\
\hline \multicolumn{3}{|c|}{ Tradisional) } \\
\hline Tidak memiliki & 27 & 90,0 \\
\hline \multicolumn{3}{|l|}{ Pendidikan Formal } \\
\hline S2 & 1 & 3,3 \\
\hline S1 & 9 & 30,0 \\
\hline D3 (Nakes) & 4 & 13,3 \\
\hline SMTA & 15 & 50,0 \\
\hline SLTP & 1 & 3,3 \\
\hline \multicolumn{3}{|l|}{ Jenis pendidikan } \\
\hline Nakes & 4 & 13,3 \\
\hline Non Nakes & 26 & 86,7 \\
\hline \multicolumn{3}{|c|}{ Mengikuti pelatihan bekam } \\
\hline Pernah & 30 & 100,0 \\
\hline Tidak pernah & 0 & 0 \\
\hline \multicolumn{3}{|l|}{ Mendapatkan sosialisasi } \\
\hline \multicolumn{3}{|l|}{ PSO bekam dari PBI } \\
\hline Pernah & 30 & 100,0 \\
\hline Tidak pernah & 0 & 0 \\
\hline \multicolumn{3}{|l|}{ Lama masa kerja } \\
\hline $0-5$ tahun & 17 & 56,7 \\
\hline$>5$ tahun & 13 & 43,3 \\
\hline \multicolumn{3}{|l|}{ Rerata jumlah klien per } \\
\hline $0-25$ orang & 13 & 43,3 \\
\hline$>25$ orang & 17 & 56,7 \\
\hline
\end{tabular}

Berdasarkan nilai mean yaitu 100,56 , ditetapkan nilai baik $=\geq 100,56$; nilai cukup $=<100,56$. Gambaran motivasi kerja pada responden praktisi yaitu terdapat 14 orang $(46,67 \%)$ responden yang memiliki motivasi kerja baik. Terdapat 16 orang $(46,7 \%)$ responden yang memiliki motivasi kerja cukup. (Tabel 2)

Tri Wahyuni Lestari', Lusitawati ${ }^{2}$, Annisa Rizky $A^{3}$, FX. Suharyanto ${ }^{4}$, Nita Prihartini ${ }^{5}$, Nurhayati ${ }^{6}$, Hadi Siswoyo ${ }^{7}$ Pusat Penelitian dan Pengembangan Sumber Daya dan Pelayanan Kesehatan Badan Litbang Kesehatan Jakarta, Indonesia E - mail: wahyuni_lestari29@yahoo.com 
KEPATUHAN PRAKTISI TERAPI TRADISIONAL BEKAM TERHADAP STANDAR PROSEDUR OPERASIONAL

Tabel 2. Gambaran motivasi responden praktisi

\begin{tabular}{ccc}
\hline $\begin{array}{c}\text { Katagori } \\
\text { Nilai }\end{array}$ & Frekuensi & Persen \\
\hline baik & 14 & 46,67 \\
cukup & 16 & 53,33 \\
Total & 30 & 100 \\
\hline
\end{tabular}

Dari 30 orang praktisi didapatkan nilai rata-rata nilai pengetahuan yaitu 8,05 (skala 10). Nilai yang dihasilkan dikatagorikan menjadi baik dan cukup. Mayoritas responden berpengetahuan baik sebanyak 14 orang $(46,7 \%)$ dan terdapat 16 orang $(53,3 \%)$ responden berpengetahuan cukup. (Tabel 3 )

Tabel 3.

Gambaran pengetahuan responden praktisi

\begin{tabular}{ccc}
\hline $\begin{array}{c}\text { Katagori } \\
\text { Nilai }\end{array}$ & Frekuensi & Persen \\
\hline baik & 14 & 46,67 \\
cukup & 16 & 53,33 \\
Total & 30 & 100 \\
\hline
\end{tabular}

Keterangan: Katagori berdasarkan nilai rata-rata 8,05 
KEPATUHAN PRAKTISI TERAPI TRADISIONAL BEKAM TERHADAP STANDAR PROSEDUR OPERASIONAL

Pengawasan atau supervisi pada fasilitas pelayanan kesehatan tradisional dapat dilakukan oleh dinas kesehatan dan juga oleh asosiasi dalam kerangka pembinaaan. Gambaran supervisi yang pernah dilakukan pada responden (Tabel 4)

Tabel 4. Gambaran supervisi pada responden praktisi

\begin{tabular}{lcc}
\hline Supervisi & Frekuensi & Persen \\
\hline $\begin{array}{l}\text { Supervisi } \\
\text { Supervisi }\end{array}$ & 28 & 93,3 \\
Dinkes/PBI & & \\
$\quad$ Pernah & & \\
$\quad$ Tidak pernah & 2 & 6,7 \\
$\begin{array}{c}\text { Supervisi Dinkes } \\
\text { Pernah }\end{array}$ & 15 & 50,0 \\
$\quad$ Tidak pernah & 15 & 50,0 \\
$\begin{array}{c}\text { Supervisi PBI } \\
\text { Pernah }\end{array}$ & 23 & 76,7 \\
$\quad$ Tidak pernah & 7 & 23,3 \\
Jumlah supervisi & & \\
Itahun & & \\
0-3 kali/ tahun & 16 & 53,3 \\
$\quad 3$ kali kali & 14 & 46,7 \\
per tahun & & \\
Terdapat & & \\
feedback & & \\
$\quad$ Ya & & 86,7 \\
Tidak & 26 & 6,7 \\
Bentuk feedback & 2 & 6,7 \\
Tertulis & 2 & 93,3 \\
$\quad$ Lisan & 28 & 100 \\
Mendapat manfaat & & 0,0 \\
dari supervisi & & \\
$\quad$ Ya & 30 & \\
Tidak & 0 & \\
\hline
\end{tabular}

Gambaran pemenuhan sarana prasarana rumah bekam yang menjadi tempat praktek responden yaitu terdapat 16 orang $(53,3 \%)$ responden yang berpraktek di rumah bekam dengan pemenuhan sarana prasarana baik. Terdapat 14 orang $(46,7 \%)$ responden yang berpraktek di rumah bekam dengan pemenuhan sarana prasarana cukup. Berdasarkan nilai median 86,67 , ditetapkan rumah bekam dengan katagori sarana prasarana baik $\geq 86,67 \%$; cukup $<86,67 \%$. (Tabel 5)

Tri Wahyuni Lestari', Lusitawati ${ }^{2}$, Annisa Rizky $A^{3}$, FX. Suharyanto ${ }^{4}$, Nita Prihartini ${ }^{5}$, Nurhayati ${ }^{6}$, Hadi Siswoyo ${ }^{7}$ Pusat Penelitian dan Pengembangan Sumber Daya dan Pelayanan Kesehatan Badan Litbang Kesehatan Jakarta, Indonesia E - mail: wahyuni_lestari29@yahoo.com 
KEPATUHAN PRAKTISI TERAPI TRADISIONAL BEKAM TERHADAP STANDAR PROSEDUR OPERASIONAL

Tabel 5. Pemenuhan sarana prasarana rumah bekam

\begin{tabular}{ccccc}
\hline Katagori Sarana prasarana & \multicolumn{2}{l}{ Jumlah rumah bekam } & \multicolumn{2}{c}{ Jumlah praktisi } \\
\cline { 2 - 5 } & Frekuensi & Persen & Frekuensi & Persen \\
\hline baik & 5 & 16 & 53,3 \\
cukup & 4 & 14 & 46,7 \\
Total & 9 & 30 & $\mathbf{1 0 0 , 0}$ \\
\hline
\end{tabular}

Katagori berdasarkan nilai rata-rata 86,67

Untuk mengetahui kepatuhan responden terhadap SPO, dilakukan observasi sebanyak 3 kali untuk melihat kekonsistenan tindakan yang dilakukan oleh praktisi. Nilai kepatuhan dalam persen didapat dari hasil observasi pada praktisi yang melakukan tindakan bekam berdasarkan kuesioner kepatuhan (SPO). (Tabel 6)

Tabel 6. Deskripsi persen kepatuhan responden praktisi bekam

\begin{tabular}{lccccc}
\hline & Frekuensi & $\begin{array}{c}\text { Persen } \\
\text { Minimum }\end{array}$ & $\begin{array}{c}\text { Persen } \\
\text { Maksimum }\end{array}$ & Rata-rata & $\begin{array}{c}\text { Standar } \\
\text { Deviasi }\end{array}$ \\
\hline $\begin{array}{c}\text { Kepatuhan thd } \\
\text { SPO (\%) }\end{array}$ & 30 & 54,83 & 94,62 & 81,44 & 8,67 \\
\hline
\end{tabular}

Untuk mengetahui faktor-faktor yang berhubungan dengan kepatuhan responden terhadap SPO dilakukan analisis bivariat. Faktor-faktor yang berhubungan dengan kepatuhan terhadap SPO $(p<0,05)$ dapat dilihat pada Tabel 7.

Tri Wahyuni Lestari', Lusitawati ${ }^{2}$, Annisa Rizky A ${ }^{3}$, FX. Suharyanto ${ }^{4}$, Nita Prihartini ${ }^{5}$, Nurhayati ${ }^{6}$, Hadi Siswoyo ${ }^{7}$ Pusat Penelitian dan Pengembangan Sumber Daya dan Pelayanan Kesehatan Badan Litbang Kesehatan Jakarta, Indonesia E - mail: wahyuni_lestari29@yahoo.com 
KEPATUHAN PRAKTISI TERAPI TRADISIONAL BEKAM TERHADAP STANDAR PROSEDUR OPERASIONAL Tabel 7. Faktor internal dan eksternal yang berhubungan dengan kepatuhan

\begin{tabular}{|c|c|c|c|c|c|c|}
\hline \multirow{2}{*}{\multicolumn{2}{|c|}{ FAKTOR EKSTERNAL/INTERNAL }} & & \multicolumn{2}{|c|}{ Kepatuhan } & \multirow{2}{*}{ Total } & \multirow{2}{*}{$P$ value } \\
\hline & & & \multirow[t]{2}{*}{ Baik } & \multirow[t]{2}{*}{ kurang baik } & & \\
\hline \multicolumn{5}{|l|}{ FAKTOR INTERNAL } & & \\
\hline \multicolumn{7}{|l|}{ 1. Pendidikan/Pengalaman } \\
\hline \multirow{4}{*}{ Jenis pendidikan formal } & \multirow{2}{*}{ Nakes } & $n$ & 3 & 1 & 4 & \multirow{4}{*}{0,469} \\
\hline & & $\%$ & $10,00 \%$ & $3,30 \%$ & $13,30 \%$ & \\
\hline & \multirow{2}{*}{ Non Nakes } & $\mathrm{n}$ & 15 & 11 & 26 & \\
\hline & & $\%$ & $50,00 \%$ & $36,70 \%$ & $86,70 \%$ & \\
\hline \multirow{4}{*}{ Tahun lulus uji standardisasi } & \multirow{2}{*}{ 0-5 tahun } & $n$ & 16 & 6 & 22 & \multirow{4}{*}{0,027 * } \\
\hline & & $\%$ & $53,30 \%$ & $20,00 \%$ & $73,30 \%$ & \\
\hline & \multirow{2}{*}{$>5$ tahun } & $\mathrm{n}$ & 2 & 6 & 8 & \\
\hline & & $\%$ & $6,70 \%$ & $20,00 \%$ & $26,70 \%$ & \\
\hline \multirow{4}{*}{ Lama masa praktek } & \multirow{2}{*}{ 1-5 tahun } & $\mathrm{n}$ & 12 & 5 & 17 & \multirow{4}{*}{0,164} \\
\hline & & $\%$ & $40,00 \%$ & $16,70 \%$ & $56,70 \%$ & \\
\hline & \multirow{2}{*}{$>5$ tahun } & $\mathrm{n}$ & 6 & 7 & 13 & \\
\hline & & $\%$ & $20,00 \%$ & $23,30 \%$ & $43,30 \%$ & \\
\hline \multirow{4}{*}{$\begin{array}{l}\text { Rerata jumlah klien per } \\
\text { minggu }\end{array}$} & \multirow{2}{*}{$1-25$ orang } & $n$ & 7 & 6 & 13 & \multirow{4}{*}{0,41} \\
\hline & & $\%$ & $23,30 \%$ & $20,00 \%$ & $43,30 \%$ & \\
\hline & \multirow{2}{*}{$>25$ orang } & $n$ & 11 & 6 & 17 & \\
\hline & & $\%$ & $36,70 \%$ & $20,00 \%$ & $56,70 \%$ & \\
\hline \multirow{4}{*}{ 2. Motivasi } & \multirow{2}{*}{ Baik } & $\mathrm{n}$ & 8 & 6 & 14 & \multirow{4}{*}{0,529} \\
\hline & & $\%$ & $26,70 \%$ & $20,00 \%$ & $46,70 \%$ & \\
\hline & kurang hoik & $n$ & 10 & 6 & 16 & \\
\hline & huraniy Noin & $\%$ & $33,30 \%$ & $20,00 \%$ & $53,30 \%$ & \\
\hline & hoik & $n$ & 8 & 6 & 14 & \\
\hline 3 Poncutahuan & & $\%$ & $26,70 \%$ & $20,00 \%$ & $46,70 \%$ & 0251 \\
\hline 0. Tengetanuali & Patsung & $\mathrm{n}$ & 10 & 6 & 16 & $0, \angle J \mid$ \\
\hline & cunup & $\%$ & $33,30 \%$ & $20,00 \%$ & $53,30 \%$ & \\
\hline FAKTOR EKSTERNAL & & & & & & \\
\hline & $>2$ & $\mathrm{n}$ & 13 & 3 & 16 & \\
\hline 1 Cunnmini & kali/tahun & $\%$ & $43,30 \%$ & $10,00 \%$ & $53,30 \%$ & 0014 * \\
\hline 1. supervist & $0-2$ & $\mathrm{n}$ & 5 & 9 & 14 & 0,014 \\
\hline & kali/tahun & $\%$ & $16,70 \%$ & $30,00 \%$ & $46,70 \%$ & \\
\hline $\begin{array}{l}\text { 2. Pemenuhan } \\
\text { Sarana/prasarana }\end{array}$ & baik & $n$ & 13 & 3 & 16 & \\
\hline & & $\%$ & $43,30 \%$ & $10,00 \%$ & $53,30 \%$ & 0,014 * \\
\hline & cukun & $\mathrm{n}$ & 5 & 9 & 14 & \\
\hline & cunup & $\%$ & $16,70 \%$ & $30,00 \%$ & $46,70 \%$ & \\
\hline
\end{tabular}

Tri Wahyuni Lestari', Lusitawati ${ }^{2}$, Annisa Rizky A ${ }^{3}$, FX. Suharyanto ${ }^{4}$, Nita Prihartini ${ }^{5}$, Nurhayati ${ }^{6}$, Hadi Siswoyo ${ }^{7}$ Pusat Penelitian dan Pengembangan Sumber Daya dan Pelayanan Kesehatan Badan Litbang Kesehatan Jakarta, Indonesia E - mail: wahyuni_lestari29@yahoo.com 
KEPATUHAN PRAKTISI TERAPI TRADISIONAL BEKAM TERHADAP STANDAR PROSEDUR OPERASIONAL

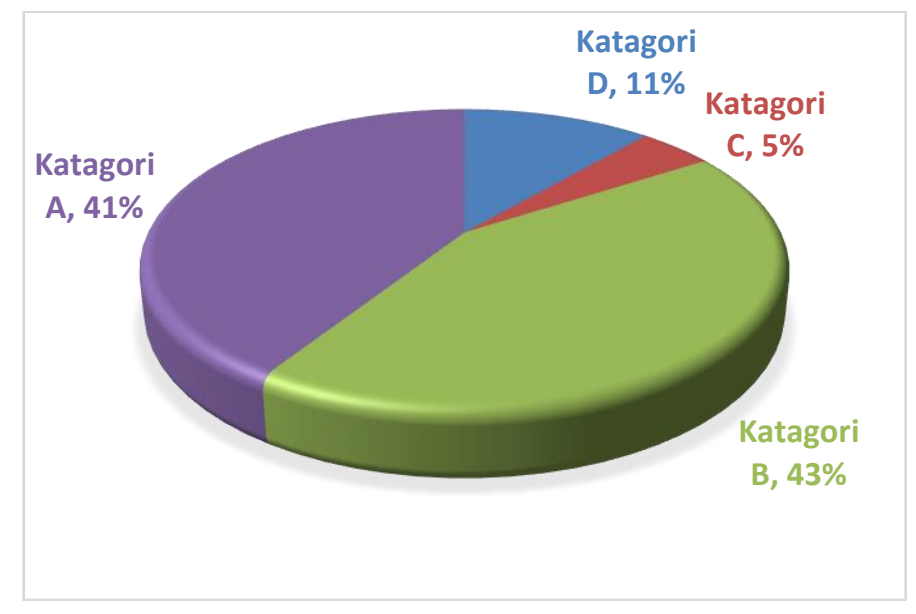

\section{Grafik 1. Kategori sarana prasarana pada PSO}

Keterangan:

Sarpras kategori A adalah sarpras yang dapat dipenuhi oleh seluruh rumah bekam Sarpras kategori B adalah sarpras yang tidak dapat dipenuhi oleh 10-29\% rumah bekam. Sarpras kategori $C$ adalah sarpras yang tidak dapat dipenuhi oleh $30-49 \%$ rumah bekam. Sarpras kategori $D$ adalah sarpras yang tidak dapat dipenuhi oleh $>50 \%$ rumah bekam.

\section{PEMBAHASAN}

Karakteristik responden praktisi dari segi usia di dominasi usia antara 31-51 tahun. Proporsi jenis kelamin responden laki-laki dan wanita seimbang. Asal wilayah responden hanya berasal dari Jakarta Selatan dan Jakarta Timur. Pada penelitian ini tidak didapatkan responden yang berasal dari Jakarta Pusat, Jakarta Utara dan Jakarta Barat, dikarenakan tidak ada responden dari daerah

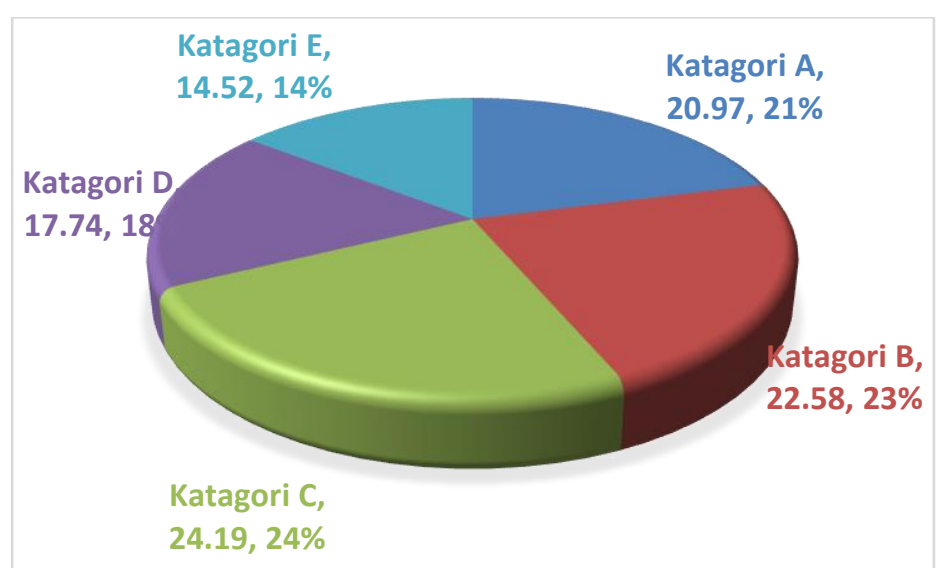

Grafik 2. Kategori butir PSO Keterangan :

Kategori $\mathrm{A}=$ butir PSO dapat dipatuhi oleh seluruh praktisi Kategori $\mathrm{B}=$ butir PSO tidak dipatuhi secara konsisten oleh 1-9\% praktisi Kategori $C=$ butir PSO tidak dipatuhi secara konsisten oleh $10-29 \%$ praktisi Kategori $\mathrm{D}=$ butir PSO tidak dipatuhi secara konsisten oleh 30-49\% praktisi Kategori $\mathrm{E}=$ butir PSO tidak dipatuhi secara konsisten oleh $>50 \%$ praktisi

tersebut yang memenuhi kriteria inklusi sebagai responden. Menurut informasi dari $\mathrm{PBI}$, anggota $\mathrm{PBI}$ banyak yang berpraktek di rumah bekam daerah Bodetabek. Hal ini disebabkan karena mahalnya sewa untuk membuka praktek rumah bekam di wilayah Jakarta.

Sebagian besar responden praktisi $(90 \%)$ tidak memiliki baik STPT dan SIPT. Menurut PP103 th 2014 pasal 39 ayat 1 dinyatakan setiap penyehat

Tri Wahyuni Lestari', Lusitawati ${ }^{2}$, Annisa Rizky $A^{3}$, FX. Suharyanto ${ }^{4}$, Nita Prihartini ${ }^{5}$, Nurhayati ${ }^{6}$, Hadi Siswoyo ${ }^{7}$ Pusat Penelitian dan Pengembangan Sumber Daya dan Pelayanan Kesehatan Badan Litbang Kesehatan Jakarta, Indonesia E - mail: wahyuni_lestari29@yahoo.com 
KEPATUHAN PRAKTISI TERAPI TRADISIONAL BEKAM TERHADAP STANDAR PROSEDUR OPERASIONAL

tradisional yang memberikan Pelayanan Kesehatan Tradisional Empiris wajib memiliki STPT. Namun menurut PMK 61 tahun 2016 pasal 4 ayat 4 disebutkan bahwa STPT hanya akan diberikan pada penyehat tradisional yang tidak melakukan intervensi terhadap tubuh yang bersifat invasif. Praktik bekam basah yang banyak dilakukan di Indonesia termasuk tindakan invasif karena melakukan perlukaan pada permukaan tubuh klien, hal ini tidak sesuai dengan PP 103 th 2014, pasal 27 ayat 1, yang menyatakan bahwa tindakan invasif tidak dapat dilakukan oleh penyehat tradisional.

Terapi dengan tindakan invasif hanya dapat dilakukan oleh tenaga kesehatan tradisional yang berpendidikan serendahnya diploma tiga bidang kesehatan.

Peraturan tersebut mendorong banyak praktisi bekam yang berusaha untuk menjalani pendidikan diploma bidang kesehatan seperti akademi perawat dsb. Hal ini juga dipertegas tentang aturan yang menyebutkan bahwa nakes dapat melakukan pelayanan kesehatan komplementer yang terdapat dalam UU no 38 th 2014 pasal 30 ayat 1 point m. Namun dalam aturan lain yaitu PMK 61 tahun 2016 Bab VII pada pasal 44 tentang Ketentuan Peralihan disebutkan bahwa pengobat tradisional yang telah memberikan pelayanan kesehatan tradisional yang bersifat invasif dan memiliki SIPT, untuk diakui sebagai tenaga kesehatan tradisional harus telah mengikuti Rekognisi Pembelajaran Lampau (RPL) atau lulus pendidikan diploma 3 yang sesuai. Dalam aturan tersebut terdapat perubahan yang awalnya dituntut untuk menjalani pendidikan diploma bidang kesehatan menjadi pendidikan diploma 3 yang sesuai dalam hal ini yaitu akademi bekam yang pada sampai saat ini belum pernah ada di Indonesia. Ketidaksesuaian praktik ini ditinjau dari persyaratan pendidikan praktisinya dengan aturan yang ada menjadikan keengganan dinas kesehatan kabupaten/kota setempat untuk mengeluarkan STPT/SIPT. Dampak diberlakukannya PP 104 tahun 2014 tentang pelayanan kesehatan tradisional dan PMK 61 tahun 2016 tentang pelayanan kesehatan tradisional empiris ini yaitu praktisi bekam tidak dapat memperpanjang SIPT nya atau membuat SIPT baru. Dalam hal pelayanan tradisional bekam, dinas kabupaten/kota hanya bersedia menerbitkan SIPT untuk bekam kering (cupping therapy).
Pada sebagian kecil responden praktisi (10\%) memiliki SIPT/STPT. Hal ini dikarenakan STPT dan SIPT yang dimiliki praktisi merupakan STPT dan SIPT dengan modalitas lainnya misal akupressure dan pijat dll. Dari segi pendidikan $50 \%$ praktisi berpendidikan SLTA, 30\% berpendidikan sarjana dan $13,3 \%$ berpendidikan dipolma nakes. Menurut PMK 61 tahun 2016 Bab VII pada pasal 44 tentang Ketentuan Peralihan, disebutkan bahwa persyaratan untuk pengobat tradisional yang telah memberikan pelayanan kesehatan tradisional yang bersifat invasif adalah diploma tiga yang sesuai. Namun hingga saat ini belum ada diploma tiga yang mengakomodir pendidikan bekam.

Prosedur Standar Operasi (PSO) bekam disusun oleh $\mathrm{PBI}$ sebagai panduan rinci bagi anggotanya untuk melakukan kegiatan bekam yang aman baik bagi klien maupun praktisi (Kudly, 2017). Standar yang jelas dan kepatuhan terhadap standar operasional prosedur dalam melakukan suatu tindakan merupakan salah satu faktor yang dapat memutus mata rantai terjadinya risiko cidera dalam memberikan pelayanan kesehatan (Fitrirachmawati, 2015).

Pada penelitian ini dilakukan observasi sebanyak 3 kali untuk melihat kekonsistenan tindakan yang dilakukan oleh praktisi. Nilai kepatuhan yang didapat dari hasil observasi pada praktisi yang melakukan tindakan bekam yaitu 81,47 persen. (Tabel 6) Dengan nilai tersebut dapat dikatakan kepatuhan praktisi terhadap SPO termasuk berkepatuhan baik. SPO yang digunakan sebagai acuan observasi adalah SPO yang dibuat oleh asosiasi dalam hal ini PBI. Beberapa orang penyusun SPO tersebut berlatar belakang medis sehingga sudah mengacu pada standar keselamatan pelayanan medis. Namun demikian SPO tersebut belum mendapat persetujuan dari Kementerian Kesehatan.

Uji standardisasi bekam merupakan standardisasi yang dilakukan oleh $\mathrm{PBI}$ sebagai syarat untuk menjadi anggota PBI agar didapatkan praktisi bekam yang kompetensinya standar. Sebelum dilakukan uji standardisasi, PBI memberikan pemaparan mengenai PSO yang telah distandarkan. Kemudian dilakukan ujian tulis dan praktek. Bagi mereka yang tidak lulus uji standardisasi tidak dapat menjadi anggota PBI. Kepada peserta yang tidak lulus dilakukan bimbingan dan pembinaan hingga lulus uji standardisasi. Dalam penelitian ini, hasil analisis

Tri Wahyuni Lestari', Lusitawati ${ }^{2}$, Annisa Rizky A ${ }^{3}$, FX. Suharyanto ${ }^{4}$, Nita Prihartini ${ }^{5}$, Nurhayati ${ }^{6}$,

Hadi Siswoyo ${ }^{7}$ Pusat Penelitian dan Pengembangan Sumber Daya dan Pelayanan Kesehatan

Badan Litbang Kesehatan Jakarta, Indonesia E - mail: wahyuni_lestari29@yahoo.com 
KEPATUHAN PRAKTISI TERAPI TRADISIONAL BEKAM TERHADAP STANDAR PROSEDUR OPERASIONAL

hubungan antara kepatuhan dengan tahun lulus uji standardisasi dengan menggunakan uji Fisher exact didapat $P$ value $=0,027$ yang berarti terdapat hubungan antara kepatuhan praktisi bekam dengan tahun lulus uji standardisasi terhadap PSO. Pada uji standardisasi didahului dengan pelatihan bekam yang kemungkinan merupakan pelatihan bekam terakhir yang diikuti oleh praktisi. Selanjutnya praktisi cenderung untuk mengikuti pelatihan lain yang bersifat pengayaan pengetahuan sebagai terapis seperti pelatihan herbal, patologi penyakit dan lain-lain. Untuk itu direkomendasikan adanya refreshing pengetahuan terhadap PSO pad anggota PBI secara berkala untuk menjaga kepatuhan terhadap PSO.

Lama praktek atau masa kerja bagi praktisi idealnya berpengaruh pada kepatuhan terhadap PSO. Semakin lama masa kerja seharusnya membuat praktisi makin mengerti tentang apa yang seharusnya dilakukan dan apa yang tidak. Dalam penelitian ini, hasil analisis hubungan antara kepatuhan dengan lama praktek dengan menggunakan uji Chi Square didapat $p$ value $=$ 0,016 yang berati tidak ada hubungan antara lama praktek praktisi bekam dengan kepatuhan terhadap PSO. Hal ini sejalan dengan penelitian yang menyatakan bahwa tidak ada hubungan antara masa kerja dengan kepatuhan perawat dalam menjalankan PSO (Fitrirachmawati, 2015). Kadang klien mencari informasi terlebih dahulu mengenai pengalaman

para praktisi bekam sebelum akhirnya memutuskan untuk melakukan terapi, kadang klien berusaha mencari informasi mengenai praktisi yang berpengalaman. (Sarkosih, 2012). Pengalaman bagi seorang praktisi meliputi lama praktek, berapa banyak klien yang sudah ditangani dan jumlah hari kerja per minggu.

Analisis statistik antara motivasi dan kepatuhan terhadap PSO, diperoleh nilai $p=0,529$ maka dapat disimpulkan bahwa tidak terdapat hubungan yang bermakna antara motivasi dan kepatuhan terhadap PSO. Hal ini tidak sesuai dengan penelitian lain yang menilai kepatuhan responden terhadap pemakaian (Alat Pelindung Diri) APD. Tingginya motivasi responden dalam penggunaan APD dikarenakan responden mengetahui dampak dari tidak memakai APD, selain itu juga dipengaruhi tingginya tuntutan tempat bekerja responden terhadap pemakaian APD. (Kasim, Mulyadi, \& Kallo, 2017).
Nilai rata-rata pengetahuan pada praktisi bekam yaitu 8,05 dengan nilai tertinggi 10,00 . Hal ini menggambarkan sebagian besar praktisi mempunyai pengetahuan yang baik. Akan tetapi, pada analisis bivariat disimpulkan bahwa pengetahuan tidak mempunyai hubungan yang bermakna dengan kepatuhan $(p=0,251)$ Hasil ini tidak konsisten dengan penelitian lain yang menyebutkan bahwa kepatuhan memiliki hubungan yang erat pengetahuan. Pekerja yang memiliki pengetahuan baik tentang PSO lebih patuh dalam menerapkan PSO bekerja di ketinggian daripada yang pekerja yang memiliki pengetahuan kurang tentang PSO bekerja di ketinggian (Dyanita, 2017).

Menurut peneliti penyebab tidak bermaknanya hubungan pengetahuan dan kepatuhan disebabkan oleh sebagian responden memiliki tingkat kefahaman yang berbeda-beda. Mereka hanya sekedar tahu namun belum sampai level memahami. Pengetahuan seseorang terhadap sesuatu memiliki tingkatan yang berbeda, dimana secara garis besarnya dibagi menjadi 6 tingkatan pengetahuan yaitu tahu (know), memahami (comprehension), aplikasi (application), analisis (analysis), sintesis (synthesis) dan evaluasi (evaluation). (Ningratri \& Wahyuni, 2015).

Berbedanya tingkat pengetahuan praktisi satu dengan lainnya, menjadikan kendala pada saat penerapan PSO ketika berpraktek. Dari hasil uji statistik antara supervisi dan kepatuhan diperoleh nilai $p=0,014$ maka dapat disimpulkan bahwa terdapat hubungan yang bermakna antara supervisi dan kepatuhan terhadap PSO. (Tabel 7) Kegiatan pengawasan terhadap para praktisi bekam dilakukan oleh pemerintah dalam hal ini dinas kesehatan dan juga asosiasi terkait dalam hal ini adalah Perkumpulan Bekam Indonesi (PBI). Sebagaimana terdapat dalam PMK 61 tahun 2016 pasal 42 yang menyatakan bahwa pemerintah pusat, pemerintah daerah kabupaten/kota melakukan pengawasan secara berjenjang dengan melibatkan institusi terkait, asosiasi penyehat tradisional dan masyarakat sesuai tugas fungsinya masing-masing (Kementrian kesehatan Republik Indonesia, 2016). Dinas kesehatan dan PBI melakukan supervisi dalam rangka bimbingan, komunikasi dan pengawasan bagi praktisi tradisional bekam.

Kegiatan komunikasi dalam supervisi mencakup penjelasan kepada staf mengenai apa

Tri Wahyuni Lestari', Lusitawati ${ }^{2}$, Annisa Rizky A ${ }^{3}$, FX. Suharyanto ${ }^{4}$, Nita Prihartini ${ }^{5}$, Nurhayati $^{6}$,

Hadi Siswoyo ${ }^{7}$ Pusat Penelitian dan Pengembangan Sumber Daya dan Pelayanan Kesehatan

Badan Litbang Kesehatan Jakarta, Indonesia E - mail: wahyuni_lestari29@yahoo.com 
KEPATUHAN PRAKTISI TERAPI TRADISIONAL BEKAM TERHADAP STANDAR PROSEDUR OPERASIONAL

yang harus dilakukan, seberapa baik mereka bekerja dan apa yang harus dikerjakan untuk memperbaiki kinerja yang masih di bawah standar. Dalam supervisi komunikasi yang efektiv sangat diperlukan agar staf mengerti apa yang disampaikan oleh supervisor dan mampu menerapkan apa yang disampaikan oleh supervisor (Fitrirachmawati, 2015).

Di negara-negara berkembang khususnya Indonesia masih memerlukan supervisi untuk meningkatkan kinerja individu. Hal ini dimungkinkan masih rendahnya kesadaran akan fungsi dan tanggung jawab tenaga kerja di Indonesia terhadap pekerjaannya. (Fitrirachmawati, 2015).

Ada hubungan antara kepatuhan praktisi terhadap PSO dengan supervisi, $\quad(p=0,014)$. Sebanyak $43,30 \%$ praktisi yang disupervisi lebih dari 2 kali per tahunnya menunjukkan kepatuhan yang baik terhadap PSO yang baik (Tabel 7).

Sarana dan prasarana pada fasilitas pelayanan kesehatan tradisional (fasyankestrad) merupakan hal sangat mendukung baik dalam proses maupun hasil pelayanan. Tersedianya sarana dan prasarana merupakan bentuk keseriusan dan tanggung jawab pengelolan fasyankestrad. Dari hasil uji statistik diperoleh nilai $p=0,014$ maka dapat disimpulkan bahwa terdapat hubungan yang bermakna antara pemenuhan sarana prasarana dan kepatuhan terhadap PSO.(Tabel 7) Tidak dapat dipungkiri bahwa alasan praktisi tidak patuh terhadap PSO adalah ketidak tersediaan sarana prasaran yang terkait dengan butir PSO. Pada Grafik 1 terdapat 11\% sarpras kategori D yaitu sarpras yaitu sarpras yang tidak dipenuhi oleh $50 \%$ rumah bekam. Selain itu terdapat 5\% sarpras kategori $\mathrm{C}$ yaitu sarpras yang tidak dipenuhi oleh $30-49 \%$ rumah bekam. Dari butir sarpras tersebut di atas, tidak ada butir sarpras yang merupakan sarpras primer, yaitu sarpras yang bila tidak

\section{SIMPULAN}

Nilai rata-rata kepatuhan praktisi bekam anggota PBI DKI Jakarta terhadap PSO yaitu 81,47 persen. Faktor-faktor yang berhubungan dengan kepatuhan praktisi terapi bekam anggota Perkumpulan Bekam Indonesia (PBI) DKI Jakarta terhadap Prosedur Standar Operasi (PSO) ada 3 variabel yaitu tahun lulus uji standardisasi, sarana prasarana dan supervisi.SARAN Pemerintah perlu terus berupaya untuk memberikan pembinaan tersedia akan secara langsung mempengaruhi keamanan klien. Jadi dapat dikatakan bahwa seluruh rumah bekam telah menyediakan sarpras yang mendukung praktek bekam yang aman untuk klien, walaupun masih terdapat ketidaksempurnaan sarana prasarana yang tersedia. Pengkategorian sarpras menjadi kategori A sd $D$ diharapkan dapat menjadi masukan bagi $\mathrm{PBI}$ untuk mengetahui jenis sarpras mana yang masih sulit dan yang telah dapat dipenuhi oleh anggota $\mathrm{PBI}$ untuk mendukung pelaksanaan praktek bekam.

Pada Grafik 2 terdapat 14,52 butir PSO kategori E yaitu butir PSO yang tidak dipatuhi secara konsisten oleh $>50 \%$ praktisi. Selain itu terdapat $17,74 \%$ butir PSO kategori D yaitu butir PSO yang tidak dipatuhi secara konsisten oleh 30 49\% praktisi. Dari butir PSO tersebut di atas, tidak ada butir PSO yang merupakan PSO primer, yaitu butir PSO yang bila tidak dilakukan akan secara langsung mempengaruhi keamanan klien. Jadi dapat disimpulkan bahwa seluruh praktisi melakukan praktek bekam dengan aman walaupun masih terdapat ketidak sempurnaan PSO yang dilakukan. Pengkategorian butir PSO menjadi kategori A sd $E$ diharapkan dapat menjadi masukan bagi $\mathrm{PBI}$ untuk mengetahui butir PSO mana yang masih sulit dan yang telah dapat diterapkan secara sempurna oleh anggota $\mathrm{PBI}$ pada saat melakukan praktek bekam.

Keterbatasan Penelitian ini yaitu penelitian hanya dilakukan pada wilayah Jakarta Timur dan Jakarta Selatan dikarenakan tidak ada responden pada wilayah Jakarta Pusat, Barat dan Utara yang memenuhi kriteria inklusi, sehingga tidak secara keseluruhan menggambarkan kepatuhan praktisi bekam di DKI Jakarta. Pemilihan kriteria inklusi sampel hanya anggota $\mathrm{PBI}$, sehingga penelitian ini tidak bisa menggambarkan pelayanan bekam basah yang dilakukan oleh praktisi bekan non PBI. kepada pengobat tradisional yang melakukan praktek invasif seperti bekam, untuk menjamin keamanan bagi klien. Perlu adanya kajian mengenai mengenai PMK 61 tahun 2016 terkait aturan yang mengatur Yankestrad empiris yang bersifat infasiv terhadap pelayanan bekam basah di Indonesia. PBI selaku asosiasi bekam, perlu melakukan penyegaran pengetahuan PSO bekam yang terkini kepada anggota PBI secara berkala.

Tri Wahyuni Lestari', Lusitawati ${ }^{2}$, Annisa Rizky A ${ }^{3}$, FX. Suharyanto ${ }^{4}$, Nita Prihartini ${ }^{5}$, Nurhayati ${ }^{6}$,

Hadi Siswoyo ${ }^{7}$ Pusat Penelitian dan Pengembangan Sumber Daya dan Pelayanan Kesehatan

Badan Litbang Kesehatan Jakarta, Indonesia E - mail: wahyuni_lestari29@yahoo.com 
KEPATUHAN PRAKTISI TERAPI TRADISIONAL BEKAM TERHADAP STANDAR PROSEDUR OPERASIONAL

\section{DAFTAR PUSTAKA}

Dyanita, F. (2018). Kepatuhan terhadap SOP Ketinggian pada Pekerja Konstruksi. The Indonesian Journal of Occupational Safety and Health, 6(2), 225-234.

Fikri, Z., Nursalam, N., \& Has, E. M. M. A. (2017). The Reduction of Cholesterol with Cupping Therapy on Cholesterol Reduction in Patients with Hypercholesterolemia. Jurnal Ners, 5(2), 195-200.

Fitrirachmawati, F. (2018). Hubungan Fungsi Supervisi dengan Kepatuhan Perawat Menjalankan SOP Identifikasi Pasien Di RSUP Dr Mohammad Hoesin Palembang Tahun 2015. Jurnal Administrasi Rumah Sakit Indonesia, 3(2).

Fitriyah, N. (2015). Pengaruh Terapi Bekam Basah Terhadap Kadar Kolesterol Total Pada Klien Diabetes Mellitus Tipe 2 Di Desa Kaliwining Kecamatan Rambipuji Kabupaten Jember.

Haryono, O. (2008). Hijamah (Bekam) Menurut Hadist Nabi SAW.

Hermalinda, H., Rustina, Y., \& Novieastari, E. (2015). Parents Experiences Using Alternative Medicine on Children Suffering Cancer in Jakarta. Jurnal Ners, 10(1), 61-73.

Hopwood, V., Lovesey, M., \& Mokone, S. (Eds.). (1997). Acupuncture and related techniques in physical therapy. Elsevier Health Sciences.

Kasim, Y., Mulyadi, \& Kallo, V. (2017). Hubungan Motivasi \& Supervisi dengan Kepatuhan Perawat dalam Penggunaan Alat Pelindung Diri (APD) pada Penanganan Pasien Gangguan Muskuloskeletal di IGD RSUP Prof. Dr. R.D. Kandou Manado No Title. E-Journal Keperawatan (e-Kp), 5.

Kuddy, A. L. (2017). Type of Leaderships, Accountability, Public Participation and Transparency of Public Policy as moderation to Degree of Legislative's Members Budgeting Knowledge in Controlling the Regional Budget (APBD). Jurnal Kajian Ekonomi dan Keuangan Daerah, 1(3).
Ningratri, P., \& Wahyuni, D. (2015). Faktor-faktor yang berhubungan dengan kepatuhan perawat dan bidan terhadap tindakan pemasangan infus dalam penerapan kewaspaaan universal di ruang rawat inap rumah sakit islam jakarta sukapura tahun 2015. Jurnal IImiah Kesehatan $M$ Thamrin, 7(1).

Purboyekti, S. Gambaran persespi masyarakat terhadap pengobatan komplementer dan alternatif di wilayah kelurahan pondok benda rw 013 pamulang 2 (Bachelor's thesis, UIN Syarif Hidayatullah Jakarta: Fakultas Kedokteran dan Ilmu Kesehatan, 2017).

Purnomo, R., Johan, A., \& Rofi'i, M. (2016). The Analysis of Factors Related to Nurse's Adherence On the Application of Standard Precautions at Banyumas General Hospital(Doctoral dissertation, Diponegoro University).

Rizkika, S., \& Restuastuti, T. (2014). Hubungan Pengetahuan dan Sikap Petugas Laboratorium Patologi Klinik terhadap Penerapan Standard Operating Procedure (Sop) Penanganan Bahan Infeksius di RSUD Arifin Achmad Provinsi Riau. Jurnal Online Mahasiswa (JOM) Bidang Kedokteran, 1(2).

Rofiq.P.A \& Ervan. (2016). Study komparasi bekam basah dan kering terhadap penurunan tekanan darah pada pasien hipertensi di griya sehat holistik keraton Kecamatan Maospati Kabupaten Magetan (Doctoral dissertation, Universitas Muhammdiyah ponorogo).

Rohatami, O., Maliya, A., Ambarwati, R., \& S Kep, N. (2015). Efektivitas Pemberian Terapi Bekam Dan Terapi Pijat Refleksi Terhadap Tekanan Darah Pada Penderita Hipertensi (Doctoral dissertation, Universitas Muhammadiyah Surakarta).

Sari, L. T., Renityas, N. N., \& Wibisono, W. (2014). The effectiveness of reflexology massage in lowering the blood pressure in elderly with hypertension. Jurnal Ners dan Kebidanan (Journal of Ners and Midwifery), 1(3), 200-204.

Widada, W. (2011). Pengaruh Bekam terhadap peningkatan Sel T CD8+ sebagai Mekanisme Pertahanan Tubuh. Pedoman penulisan artikel, 219.

Tri Wahyuni Lestari', Lusitawati ${ }^{2}$, Annisa Rizky A ${ }^{3}$, FX. Suharyanto ${ }^{4}$, Nita Prihartini ${ }^{5}$, Nurhayati ${ }^{6}$, Hadi Siswoyo ${ }^{7}$ Pusat Penelitian dan Pengembangan Sumber Daya dan Pelayanan Kesehatan Badan Litbang Kesehatan Jakarta, Indonesia E - mail: wahyuni_lestari29@yahoo.com 